\title{
Virtual Training Application by Use of Augmented and Virtual Reality under University Technology Enhanced Learning in Slovakia
}

\author{
Gabriela Gabajová ${ }^{\circledR}$, Beáta Furmannová, Iveta Medvecká, Patrik Grznár *®D, Martin Krajčovič \\ and Radovan Furmann \\ Faculty of Mechanical Engineering, University of Žilina, Univerzitná 8215/1, 01026 Žilina, Slovakia; \\ gabriela.gabajova@fstroj.uniza.sk (G.G.); beata.furmannova@fstroj.uniza.sk (B.F.); \\ iveta.medvecka@fstroj.uniza.sk (I.M.); martin.krajcovic@fstroj.uniza.sk (M.K.); \\ radovan.furmann@fstroj.uniza.sk (R.F.) \\ * Correspondence: patrik.grznar@fstroj.uniza.sk; Tel.: +421-41-513-2733
}

Received: 10 October 2019; Accepted: 22 November 2019; Published: 26 November 2019

\begin{abstract}
The use of modern information and communication technologies plays a key role in the current global competitive environment of long-term manufacturing company sustainability. Based on the requirements of Slovak industrial companies (both domestic and foreign companies), there is a need to implement these technologies into the university teaching process. Therefore, this article describes virtual and augmented reality applications into the teaching process of Digital Factory module at the Industrial Engineering Department of the University of Zilina. The main aim of this study was to test and document how helpful immersive technologies could be in a teaching process. There were a group of students who took part in this study whose job was to assemble a specific assembly construction, first without the help of virtual technologies and second with the help of augmented and virtual reality. The results were collected through operation images and chronometry, these were then analyzed the conclusions stated in the article were obtained. In the conclusion, the final part of the article describes a general evaluation of virtual training use in the industrial practice of long-term industrial company sustainability.
\end{abstract}

Keywords: technology enhanced learning; advanced industrial engineering; innovative technologies; immersive technologies; virtual reality; augmented reality; case study

\section{Introduction}

In today's globalized world, organizations learn how to manage knowledge-based resources from global leadership companies. The use of information and communication technologies, different tools, and knowledge management strategies in organizations can lead to innovation. These innovations occur in services, products, and processes, and maintain competitive advantages in globalized economies around the world [1].

The education sector has been under constant pressure in recent years. Education is not resistant to progress in information and communication technologies [2]. There are major demands on educational systems around using new sophisticated technologies to teach students, especially for providing the knowledge and skills that are needed in this century [3]. This topic has become a key issue and is being discussed regarding the range from preschool to higher education [2]. Sustainable development of organizations around the world requires quality education, which can be a key to this development $[4,5]$. Technology is a supportive learning tool when we can use digital learning materials [6]. We can use technology to improve the process of acquiring skills, especially in critical thinking and with the 
right of individuals to seize opportunities and use their potential [4]. The interaction of behavior and information technology has recently become a challenge for emerging technologies [7], including virtual reality. Virtual reality technologies and their applications are constantly improving and we look at them from different perspectives [8]. Virtual reality technology has been used in various disciplines. It is used in aviation to develop virtual flight simulators [9]. It also is used as a recruiting tool in the military [10] and to train soldiers by creating a virtual combat environment [11]. Virtual reality has also been used to visualize research outputs in fields such as cosmology [12], magnetohydrodynamics, and aerodynamics $[13,14]$, which helped to improve scientific insight and interpretation. We can also find virtual reality in journalism that is helping to increase a story's impact on audiences [15], as well as in healthcare and medicine (such as for the treatment of post-traumatic stress disorder) [16].

Nowadays, virtual reality applications in learning represents an interesting area. Some information systems provide different services to all stakeholders (students, academics, managers, and professionals) [8]. In education, this is a key strategic shift in focus from a basic knowledge-based primary education to education enriched with dynamic media [17]. The introduction of new technologies into the teaching process has a high potential. Inclusive education is an innovative approach in the field of education, which in particular highlights the right of every individual to a quality education [18]. According to reference [2], the "definition of education points out the decisive role of technology-enhanced education against boosting technological innovativeness, strengthening the economy, enhancing awareness of environmental sustainability, and ultimately empowering people to secure their wellbeing".

The Department of Industrial Engineering in Žilina is focused on industry, industrial production, and improvement of its processes. Industry 4.0 can be considered as a paradigm shift in the industry that aims at combining all the production agents (machines, robots, and operators) in the shape of Cyber Physical Systems by means of network connections and information management [19]. Industry 4.0 can also be called a digital revolution. It is characterized by a combination of technologies that remove the boundaries between physical, digital, and biological spheres. Today, market variability is increasing, the product life cycle is shortening, product complexity is growing, and global supply chains are increasingly influenced. In this environment, organizations strive to become more flexible, cheaper, faster, and more responsive to business trends. Industry 4.0 provides solutions and ways for organizations to meet these challenges (using Internet of Things, cloud computing, collaborative robots, and immersive technologies) [20]. One of the active challenges of the industry is the management of knowledge [21]. Expert operators acquire valuable knowledge about the manufacturing processes over the years. For instance, this knowledge can be related to the efficient management of processes or the disassembly, inspection, maintenance, and assembly of machines. The transference of this knowledge to new operators is a key issue. However, this transference is sometimes not efficient or does even not take place, endangering the future of organizations [22].

The basic principle of modern learning theories lies in different kinds of learning goals that require different approaches to learning and these new learning goals require changes in learning opportunities. Concept Technology-enhanced learning (TEL) represents the application of technology in teaching and learning. TEL environment supports the gradual development of higher-order skills (such as critical thinking and learning based on exploration problems). Computing combines TEL with computer science and individual technologies create opportunities for more effective learning and learning through new types of knowledge and skills [23].

This is one of the reasons why we tried to apply new immersive technologies to the teaching process at the university and bring some elements of Industry 4.0 from the industrial practice in the context of the long-term sustainability of industrial enterprises.

\section{Materials and Methods}

A time study was used for a case study in the education process of an industrial plug assembly. Image operation was used as a method to measure the time needed for an industrial plug assembly. This is a method of direct time use measurement with the use of a chronometric device (stopwatch). 
The most common method of image operation is the chronometry, which represents a method of continuous time use observation for all operations examined. It is suitable for a sequence and number of regularly repeating operations. The most important part of the method was to monitor time consumption for each part of the entire assembly process and to write these down on chronometric paper. Furthermore, the results of this measurement were then statistically analyzed and conclusions were made. These could be found in the results section.

First, when making virtual training in virtual and augmented reality, Autodesk Maya 3D objects were created according to a sample of real industrial plugs. These models were subsequently exported into the programming development environment Unity 3D, where assembly logic, procedure, and object interaction of the entire virtual training was defined.

Depending on a final type of training, whether it was to be displayed in virtual reality (HTC Vive Pro used) or augment reality (tablet Samsung S5 used), different work procedures and libraries Steam VR in Unity 3D environment were used. The SteamVR plugin is necessary to allow the integration of the developed code with the head mounted display and hand controllers [20].

\section{Virtual Training}

Virtual training is a form of training done in a virtual or simulated environment. The lecturer and student do not even have to be in the same room. The virtual training at university is designed in a way so that it could simulate traditional teaching or teaching experience.

The virtual training is close to reality thanks to an application of virtual and augmented reality and technologies, which try to create as faithful object in space display as possible, as well as its manipulation and movement in a 3D environment and in real time.

There are a few display devices, which could be used for virtual training in augment reality and mixed reality:

- mobile phone on its own or connected to Virtual Reality 3D glasses (e.g., Evolveo VRC-4),

- tablet with Android platform or Apple iPad,

- glasses for augmented reality—either viedo see-through or optical see-through [24], for example smart glasses from Vuzix,

- glasses for mixed reality-Microsoft Hololens,

- LCD monitor or touchscreen monitor.

The following devices could be used as a display device for virtual training in virtual reality:

- virtual reality glasses—set which allows immersion into the virtual reality contains HMD (Head Mounted Display) and controls. Virtual Reality glasses HTC Vive Pro have base stations, monitoring user's movement in the room. Another option for virtual training in virtual reality is Oculus Rift VR device.

- CAVE (Computer Assisted Virtual Environment)—projects images on the wall, floor and ceiling. In the room, so called cave, the user must wear special glasses and his movement is limited to a selected area, made of walls, as can be seen in Figure 1. The main advantage of CAVE is a possibility to share experiences. The main disadvantage is the cost and space requirements for this display device [25].

Making of virtual training has its procedure, which is shown in Figure 2. It is implemented in a selected platform. There are several platforms, which could be used at universities, and 3D Unity, Unreal studio, and the Ella platform are the most commonly used platforms in Slovakia. 


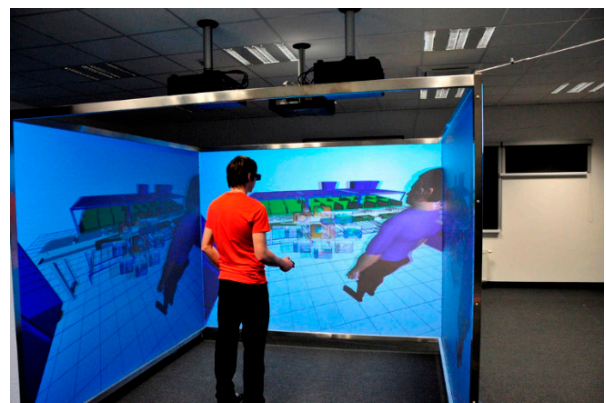

Figure 1. CAVE (Computer Assisted Virtual Environment).

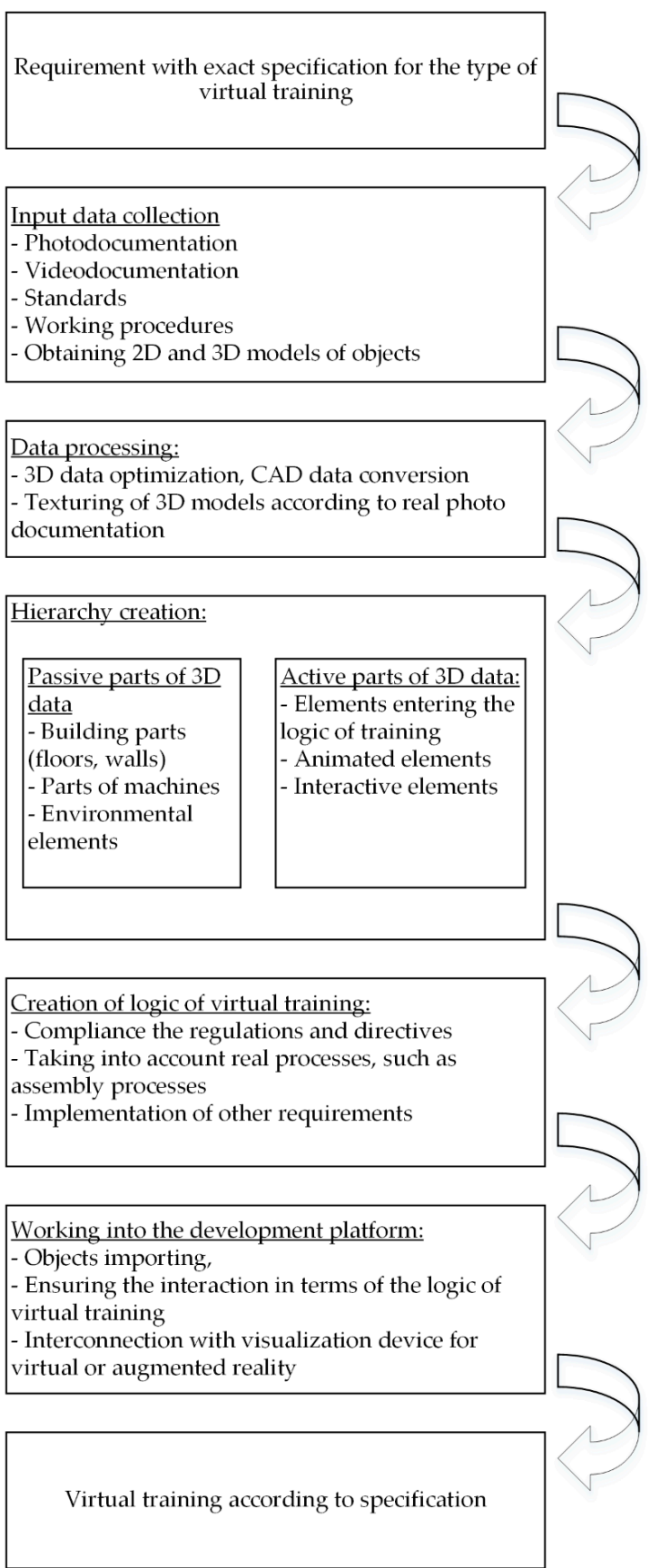

Figure 2. Virtual training procedure making. 


\section{Case Study}

\subsection{Task Definition}

The case study was realized at the Department of Industrial Engineering, Faculty of Mechanical Engineering at University of Žilina, Digital Factory subject. The aim of the research was to find out how the implementation of new technologies (virtual and augmented reality) contributes to the teaching process at the Department of Industrial Engineering within the subject Digital Factory. Further, we sought to find out if these technologies have benefits and improve processes or do not contribute to any significant degree.

The main task of the case study was to find out how virtual element use contributes to overall time reduction needed for assembly implementation. Thirty students, divided into groups of three, participated in this study. These groups were made to obtain more real results, as the industrial plug assembly procedure was easy to remember. In case, all three groups would have participated in all three assembly cases, as the results would not have been relevant. Special criteria for the selection of students have not been established. The study was attended by engineering students aged between 23 and 26 years. The specialization of all three groups was the Industrial Engineering study field. Of the total number of participating students, $64 \%$ were men and $36 \%$ were women. The only limitation in grouping students was the use of eyeglasses, which restricted participants from using the HTC Vive Pro for virtual reality.

The first group of students was monitored and measured when assembling an industrial plug without a use of virtual elements. Therefore, only a paper manual was used. Next, a second group of students was given an assembly manual displayed on a tablet by augmented reality. Finally, a third group of students tried to assemble an industrial plug with the help of virtual training and was at the same time meant to assemble the industrial plug without any further help. In other words, these students were not given any paper manual or manual on a tablet device.

Industrial plug assembly with its BOM (Bill Of Material) is displayed in Figure 3.

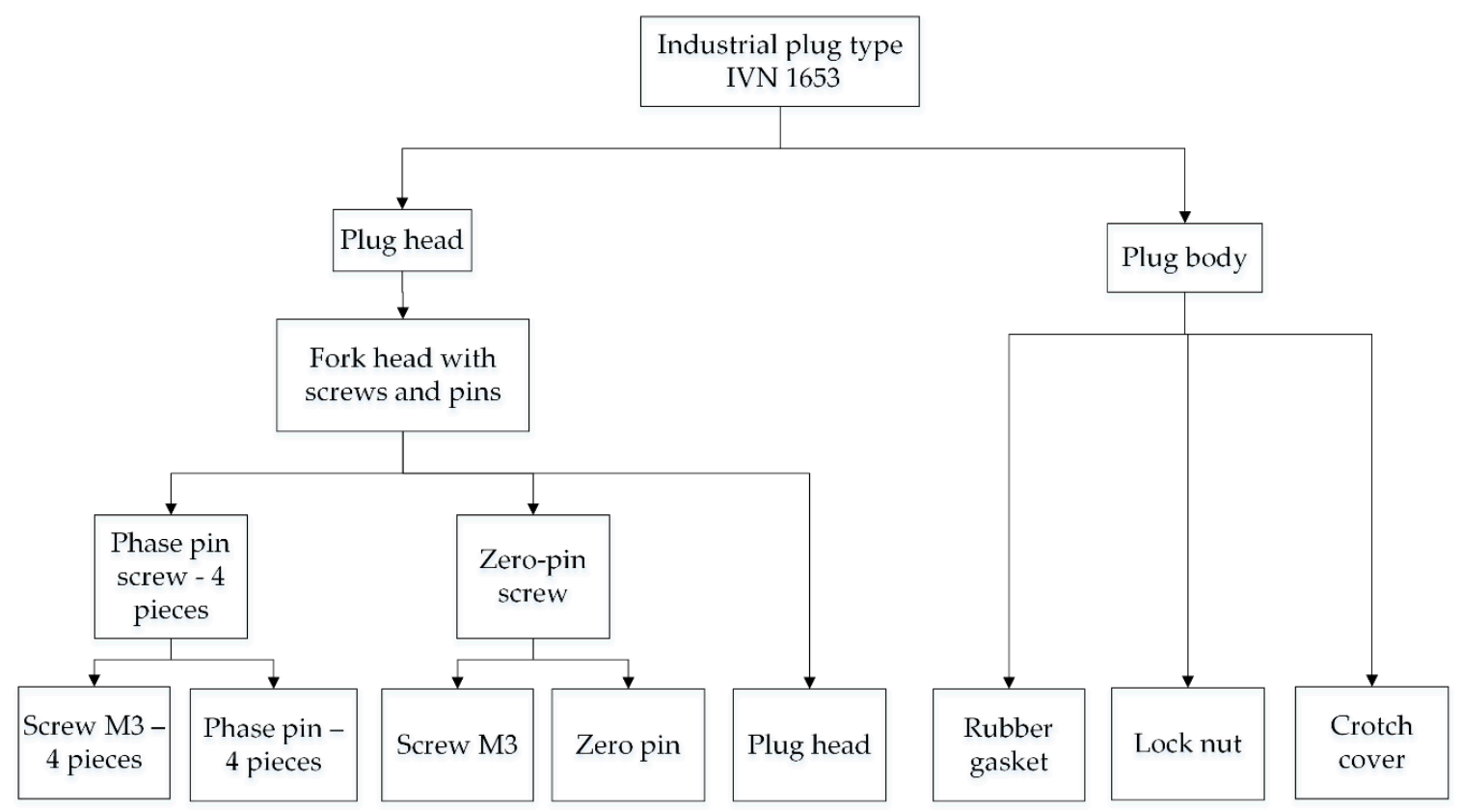

Figure 3. Industrial plug BOM (Bill Of Material).

The industrial plug assembly procedure was divided into five basic phases displayed in Table 1. 
Table 1. The main assembly parts and description of activities.

\begin{tabular}{cc}
\hline Part & Description of Activities \\
\hline Phase 1 & $\begin{array}{l}\text { Screw the screw_1 M3 into the phase pin_1 } \\
\text { Screw the screw_2 M3 into the phase pin_2 } \\
\text { Screw the screw_3 M3 into the phase pin_3 } \\
\text { Screw the screw_4 M3 into the phase pin_4 }\end{array}$ \\
\hline Phase 2 & Screw the screw_5 M3 into the zero pin \\
Phase 3 & Press the zero and phase pins with the screws into the fork head \\
Phase 4 & Mount the rubber gasket, lock nutnut and crotch cover \\
Phase 5 & Mount the plug head with the plug body \\
\hline
\end{tabular}

Operations $T_{1}, T_{2}, T_{3}, T_{4}, T_{5}$ and their time duration for each phase were monitored and measured by a stopwatch (time was measured in seconds). The results were written down in chronometry list (Figure 4). This data was statistically processed and provided basic information to make a conclusion.

\begin{tabular}{|l|l|l|}
\hline \multicolumn{2}{|c|}{ CHRONOMETRY LST } \\
\hline \multicolumn{2}{|c|}{ BASIC DATA } \\
\hline Subject & Digital Fatory & Time study for: \\
\hline Study group & & Virtual reality \\
\hline Number of students & & Augmented reality \\
\hline Date & $\square$ \\
\hline Responsible pers on & & Paper form \\
\hline
\end{tabular}
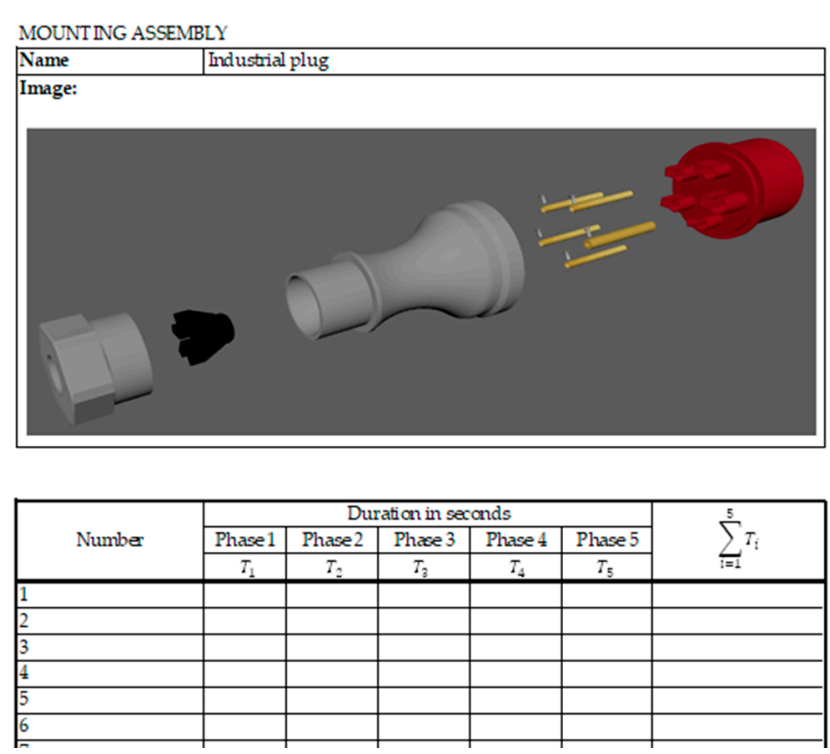

Figure 4. Chronometry list.

\subsection{Assembly with User Manual}

First group of students monitored when assembling an industrial plug was given a user manual, as it can be seen in Figure 5. None of the elements of virtual reality were used. Each time duration $T_{1}, T_{2}, T_{3}, T_{4}, T_{5}$ for operations Phase 1 - Phase 5 was written down in the chronometry list and evaluated afterwards. 


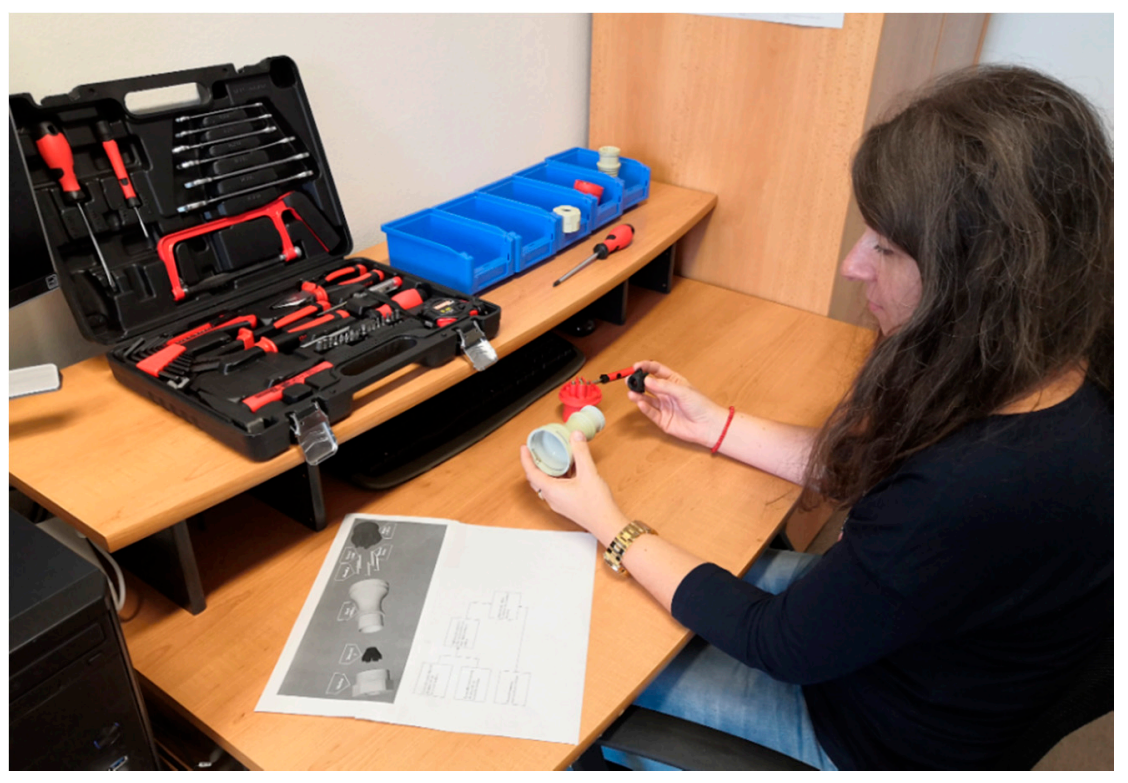

Figure 5. Industrial plug assembly process with a user manual only, without using virtual reality.

Results achieved (with maximum and minimum assembly time duration) from the measured data for statistic sample of thirty students are shown in Figure 6. This implies that the total time needed for a socket assembly with a user manual is only an average of $177 \mathrm{~s}$.

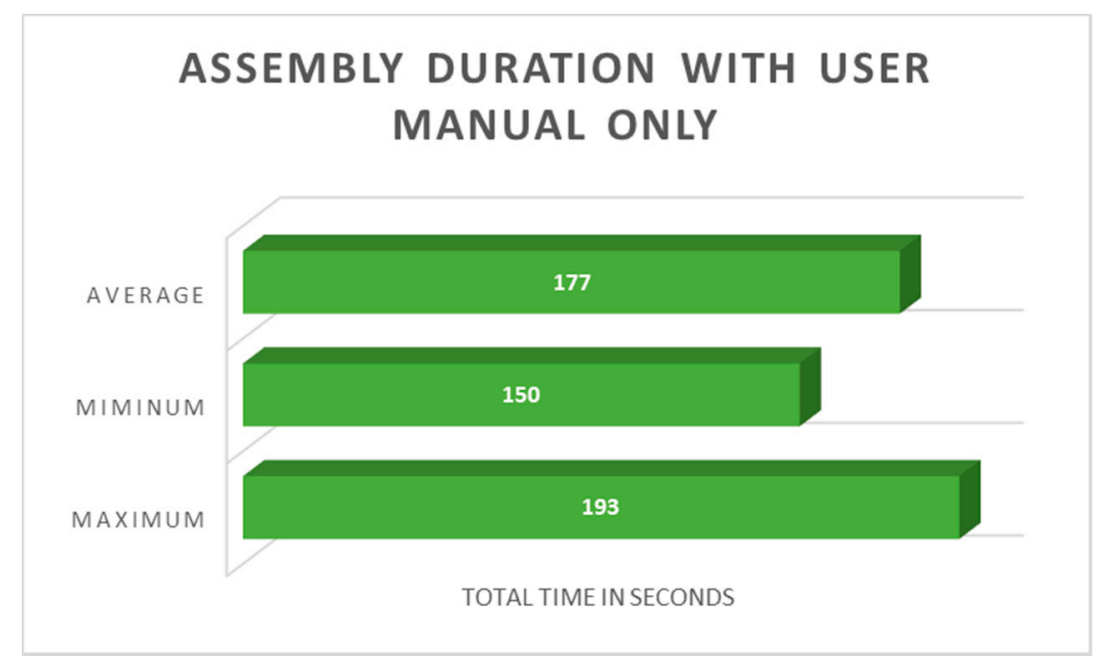

Figure 6. Industrial plug assembly duration with a user manual only (no use of virtual reality).

\subsection{Assembly with Augmented Reality}

A second group of students monitored when assembling a socket was given a manual with the use of augmented reality, as can be seen in Figure 7. Each step of the assembly procedure was displayed in augmented reality on a tablet. Each time duration $T_{1}, T_{2}, T_{3}, T_{4}, T_{5}$ for operations Phase 1-Phase 5 were written down in a chronometry list and evaluated afterwards. 


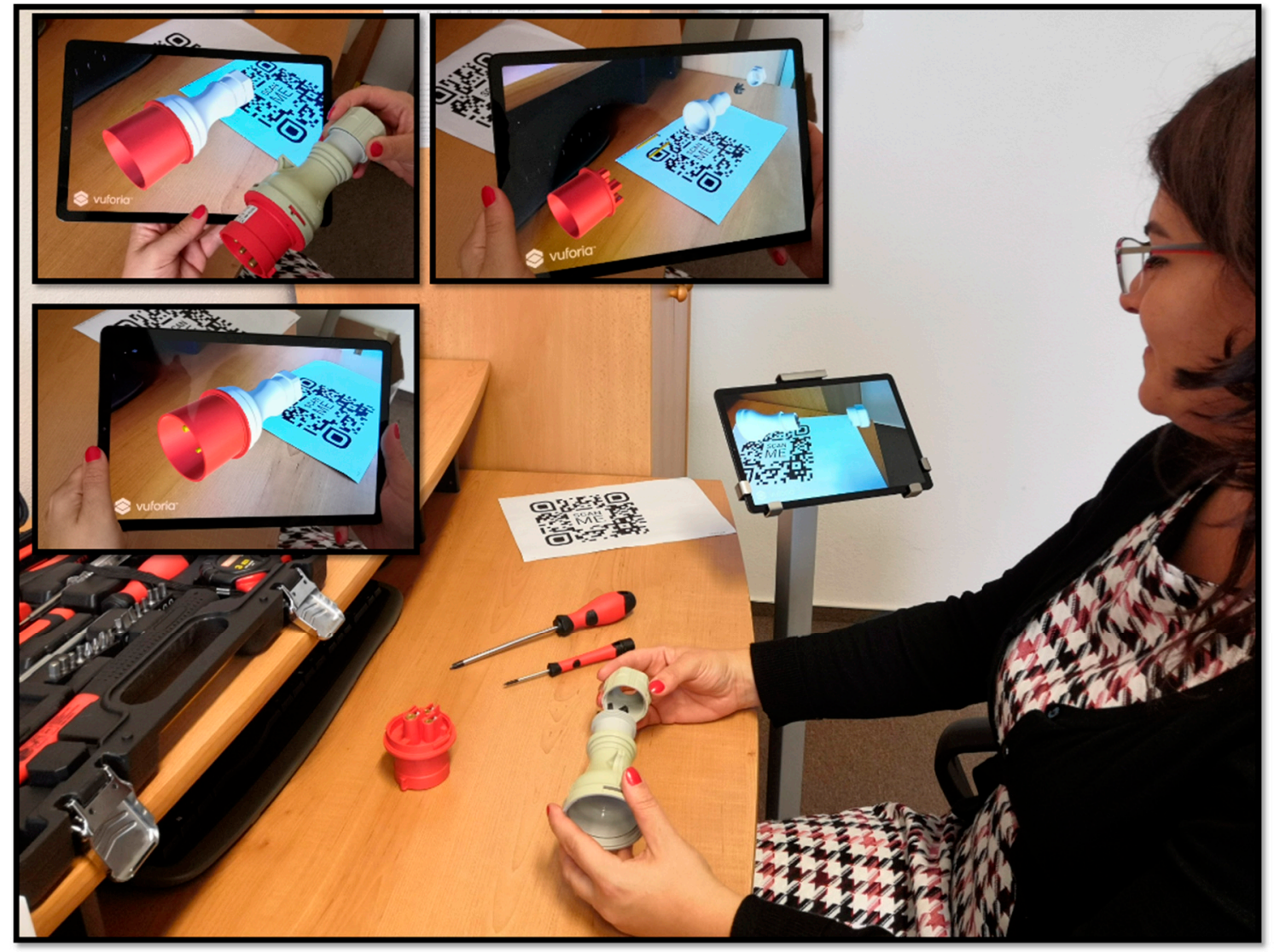

Figure 7. Industrial plug assembly with the use of augmented reality.

Results achieved (with maximum and minimum assembly time duration) from the measured data for statistic sample of thirty students are shown in Figure 8. This implies the total time needed for a socket assembly with use of augmented reality is by an average of $113 \mathrm{~s}$. The average time needed for assembly was in this case reduced by $64 \mathrm{~s}$.

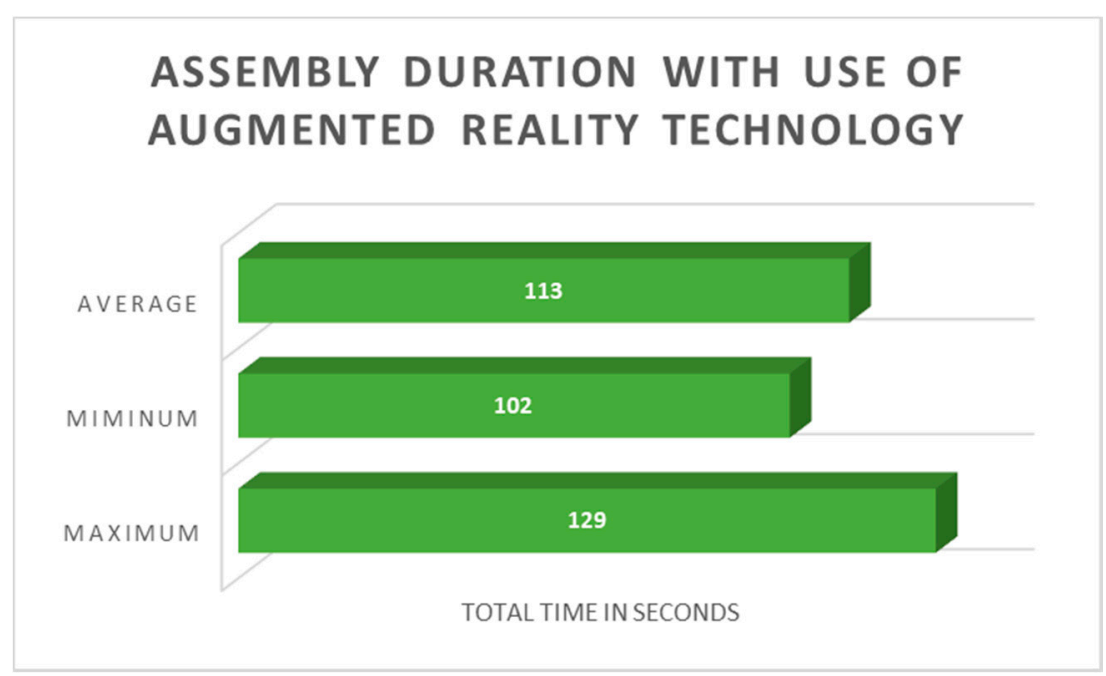

Figure 8. Industrial plug assembly duration with use of augmented reality technology. 


\subsection{Assembly with Use of Virtual Reality and Virtual Training}

The third group of students was monitored when assembling an industrial plug in virtual reality with use of virtual training. These students were not offered any further help with industrial plug assembly (neither user manual nor tablet with augmented reality). Virtual training was created in the developing programming environment Unity 3D with Steam VR library help. HTC Vive Pro was used as a display device. This can be seen in Figure 9. Each operation and its time duration was written down in a chronometry list and evaluated afterwards.

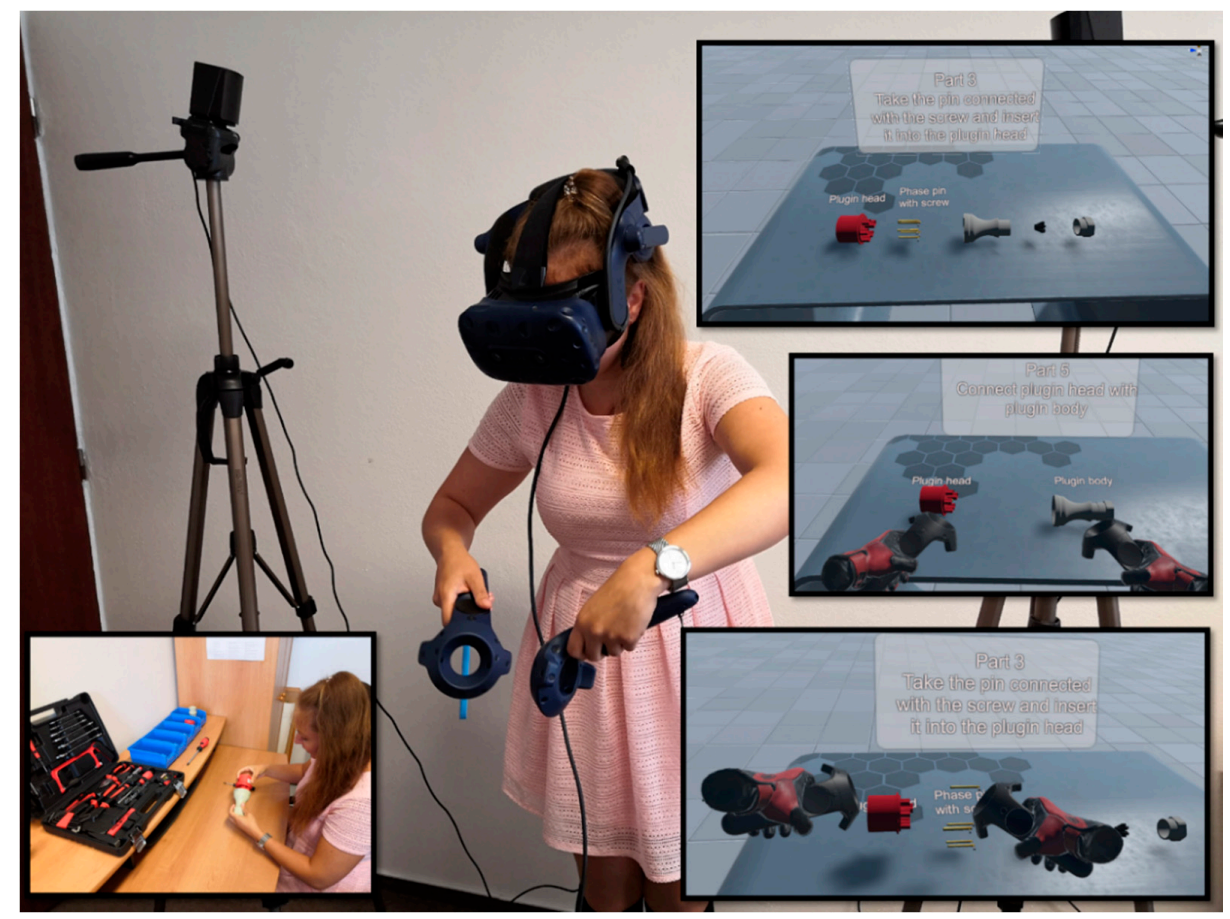

Figure 9. Industrial plug assembly with the use of vitual reality and virtual training.

Results achieved (with maximum and minimum assembly time duration) from the measured data for statistic sample of thirty students are shown in Figure 10. This implies that the total time needed for an industrial plug assembly with the use of virtual reality and virtual training is an average of $99 \mathrm{~s}$. The average time compared to a user manual was reduced by $78 \mathrm{~s}$ and in the case of augmented reality was reduced by $14 \mathrm{~s}$.

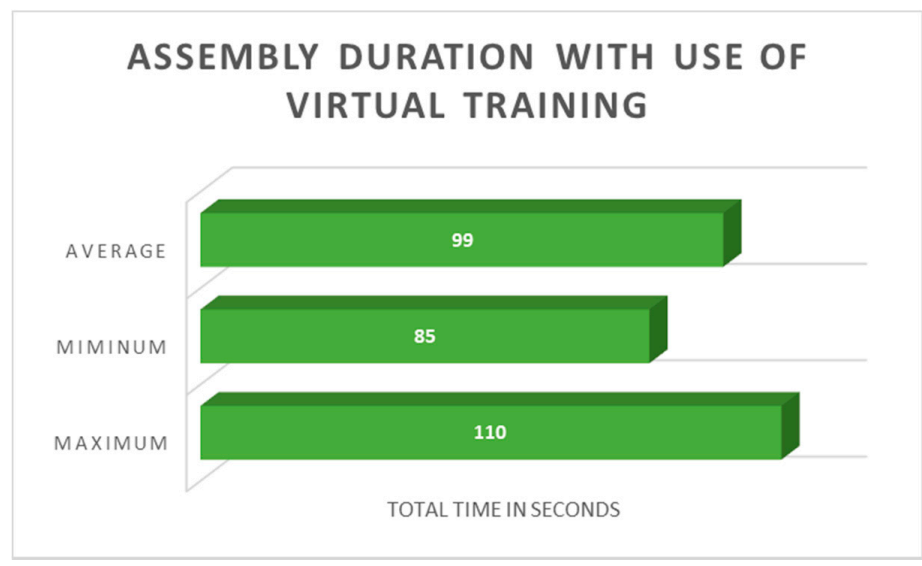

Figure 10. Industrial plug assembly duration with the use of virtual reality technology and virtual training. 


\subsection{Result Evaluation}

The following statistic quantities were monitored in all three groups:

- Arithmetic mean $\bar{x}$ (1)—statistic quantity showing a typical value describing a set of multiple values.

$$
\bar{x}=\frac{\sum_{i=1}^{n} x_{i}}{n}[\mathrm{~s}]
$$

- Variation range $R$ (2)-points out difference of a set of extreme values (maximum and minimum value difference).

$$
R=x_{\max }-x_{\min }[\mathrm{s}]
$$

- Measurement realibility $K_{r}$ (3)—range coefficient checks measurement realibility, applying to $K_{r} \leq 1.5$.

$$
K_{r}=\frac{x_{\max }}{x_{\min }}
$$

- Determinant range $S$ (4) —expresses quadratic average of value deviation from an arithmetic average.

$$
S=\sqrt{\frac{\sum_{i=1}^{n}\left(x_{i}-\bar{x}\right)^{2}}{n-1}}[\mathrm{~s}]
$$

- Selective diameter fault $e_{r}$ (5)—sets arithmetic mean deviation from a real value. Certain elective fault is a necessary chracterstic of each sample. Major selective fault prevents so-called external reasearch validity.

$$
e_{R}=\frac{\frac{S}{\bar{x}}}{n-1} \times 100[\%]
$$

- Measurement results from the stated statistic quantities are shown in Table 2.

Table 2. The main assembly parts and description of activity.

\begin{tabular}{cccc}
\hline Statistics & Paper Form & Augmented Reality & Virtual Reality \\
\hline Arithmetic mean $\bar{x}[\mathrm{~s}]$ & 177 & 133 & 99 \\
Variation range R [s] & 43 & 27 & 25 \\
Measurement realibility $K_{r}$ & 1.287 & 1.265 & 1.294 \\
Determinant range $S[\mathrm{~s}]$ & 9.87 & 6.02 & 5.28 \\
Selective diameter fault $e_{R}[\%]$ & 0.19 & 0.18 & 0.18 \\
\hline
\end{tabular}

By using the given date, it is possible to assess when the highest average time for a total industrial plug assembly was needed when assembling with a user manual (paper form). The use of augmented reality technology saved $36.16 \%$ of the average time needed. The use of virtual training represented $44.07 \%$ of average time needed for the assembly. The mutual comparison of average time consumption for industrial plug in all three assembly cases is shown in Table 3 and Figure 11.

The coefficient range $K_{r}$ was in all three cases smaller than a value of 1.5. Therefore, it can be stated that the measurement realibility was kept. Selective diameter fault was kept in low values, it did not pass $1 \%$.

Table 3. Overall average time saved needed for assembly.

\begin{tabular}{cc}
\hline Comparison & Saving in \% \\
\hline Paper form-Augmented reality (AR) & 36.16 \\
Paper form-Virtual reality (VR) & 44.07 \\
Augmented reality (AR)—virtual reality (VR) & 12.39 \\
\hline
\end{tabular}




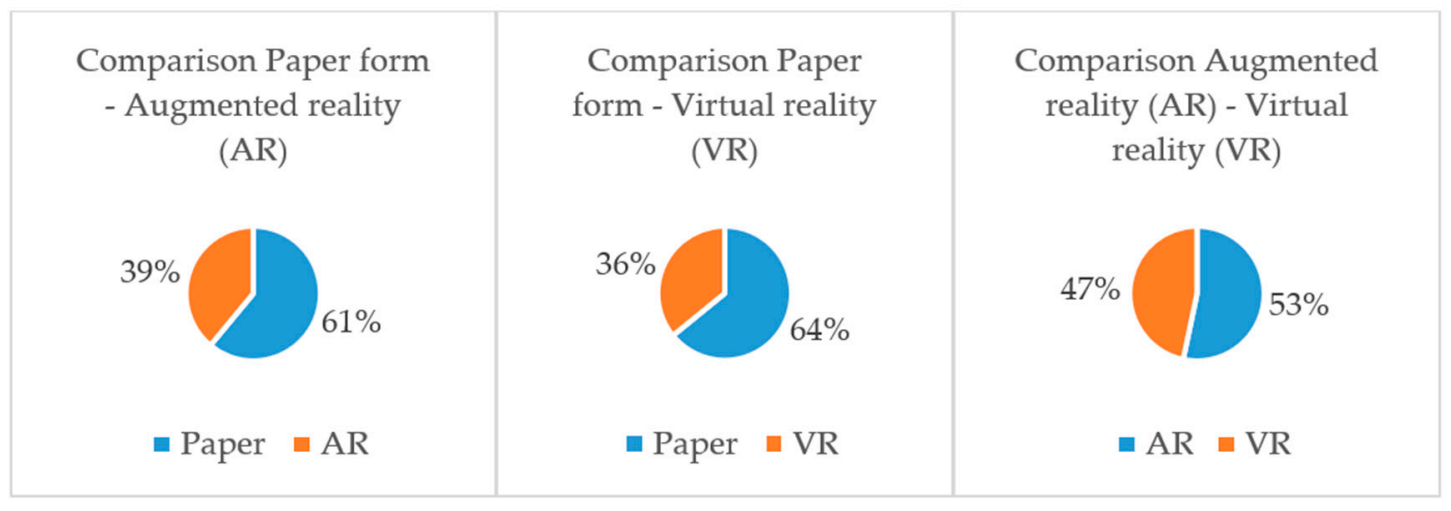

Figure 11. Comparison of overall average time asembly duration in $\%$.

The analysis points out that the use of augmented and virtual reality significantly reduces the time needed for industrial plug assembly. The most significant difference can be seen when comparing the time needed for assembly with user manual (paper form) and virtual training. There is also a difference between the use of augmented and virtual reality, but it is not as significant. Therefore, it is not possible to decide what technology is more efficient, even though the total time needed for assembly with virtual reality was reduced by $12.39 \%$, compared with the augmented reality. Moreover, the technology of augmented reality also belongs into the category of virtual reality, that is why it is possible to consider them both equally [26].

As for comparison of average assembly duration time for each parts of Phase 1 up to Phase 5, all results can be found in Table 4 and Figure 12.

Table 4. Total average time saved needed for assembly.

\begin{tabular}{cccc}
\hline \multirow{2}{*}{ Part } & \multicolumn{3}{c}{ Total Average Time Saved Needed for Assembly in Seconds } \\
\cline { 2 - 4 } & Paper Form & Augmented Reality & Virtual Reality \\
\hline Phase 1 & 81 & 60 & 51 \\
Phase 2 & 23 & 14 & 10 \\
Phase 3 & 24 & 13 & 12 \\
Phase 4 & 34 & 18 & 16 \\
Phase 5 & 16 & 10 & 9 \\
\hline
\end{tabular}

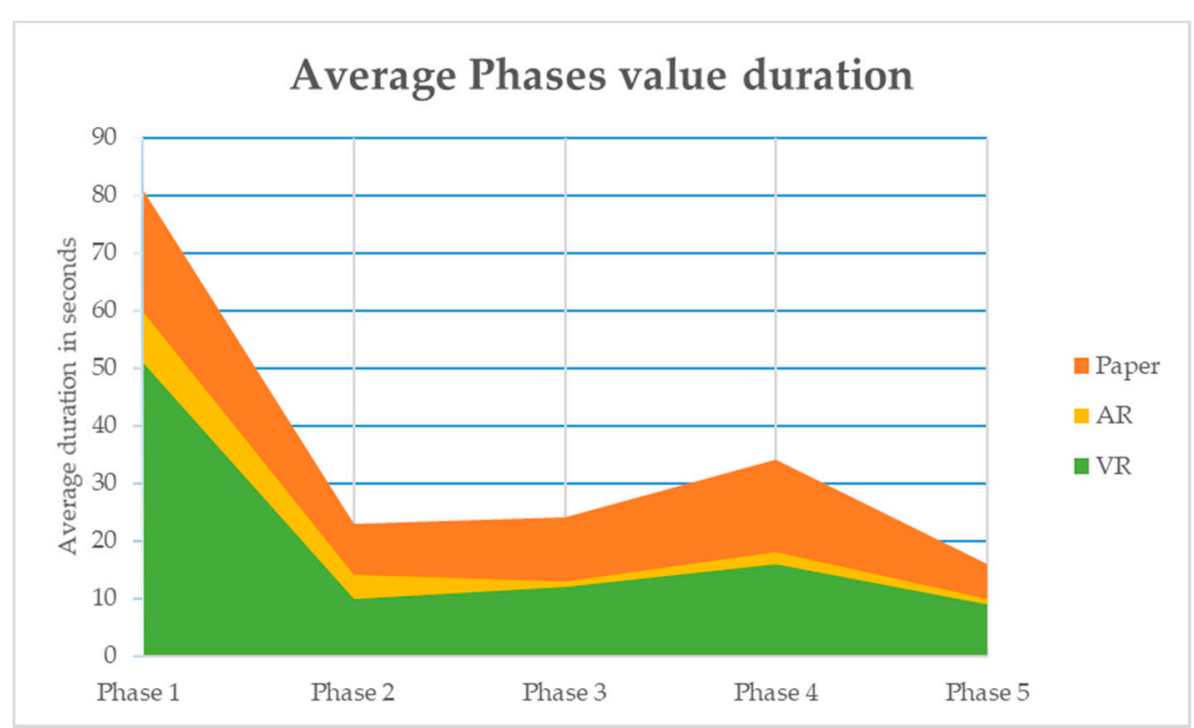

Figure 12. The average value of Parts duration in seconds 
Figure 12 points out that virtual reality significantly helped students when assembling an industrial plug in Phase 1 and Phase 4, which is very important for a successful assembly of an industrial plug. Also, it could be stated that due to significant improvements in parts Phase 1 and Phase 4, the average assembly time can be reduced.

The results of the case study show that the introduction of modern technologies into the teaching process is well founded. The main benefits of case study results are:

- confirmation that the implementation of virtual and augmented reality in learning processes is well founded, and accelerates and improves learning processes,

- virtual training provides students with an environment where they can safely learn and acquire new experiences and skills, which they can later use in practice,

- confirmation that the use of virtual elements in the teaching process gives students a different perspective towards teaching methods and motivates them.

The main benefits of implementation the virtual and augmented reality technologies into the teaching process within universities and their technical subjects includes:

- improving, accelerating, and modernizing teaching and learning processes,

- improving the imagination of processes,

- wide range of areas and subjects on which virtual trainings can be created,

- possibility to test the processes without the risk of consequences.

\section{Discussion}

The following questions have arisen:

\subsection{What are the Main Advantages of Virtual Trainings?}

One of the biggest advantages of virtual trainings is that a student can personally experience it. The fact is that a person can try it, then he or she will remember it better than reading a manual in paper form. It is possible to try almost everything in virtual reality. This means if we want to change something or improve a certain process in a company, we can try various solutions using a simulation. When there is a situation in a real environment, it is difficult to imagine processes changing. Thanks to virtual reality, all possible variations could be tested and without physically changing something when deciding. This way a company can save a lot of money. Another advantage of virtual training in industrial practice is that a new employee learns by himself and there is no need to have another employee standing next to him and teaching him. Again, a company is able to save a lot of money and time, as the main employee does not need to keep digressing from his main task. Furthermore, another advantage is that there is a large number of virtual training uses in various sectors, such as, healthcare, army, games, interier design, marketing, and many more. Based on the case study, it can be noted that assembly with use of virtual training was less time consuming. In other words, it significantly contributed to the time reduction needed for industrial plug assembly. Students were able to quickly familiarize themselves with the type of work they were doing, they were also able to memorize the assembly procedure quicker, which resulted in higher motivation and a faster assembly.

\subsection{Are There Any Disadvantages of Virtual Training Use?}

Yes, virtual training technologies implemented in a teaching process or experience also have disadvantages. One of the biggest disadvantages is the challenge of virtual reality training for older people. The problem is that older people are not used to these new technologies, so they can get dizzy when using virtual glasses and they find it unpleasant in general. Virtual reality headsets used for computers are connected via cables. It would not be possible to work without them. However, the disadvantage of this is that a cable only allows movement to a certain distance, meaning there is a danger of stumbling or ripping the cable off. Also, one of the main disadvantages is that virtual 
reality headsets have limited resolution for a human eye. Virtual glasses usually have a resolution of $1440 \times 1600$ for an eye, which is sufficient but is not ideal. In order to display 3D models in virtual reality, it is necessary to simplify them. This then reduces the visual quality. This means that when a person is looking at objects and their attention is focused on them, these objects must be displayed with the highest quality during virtual training. On the other hand, objects that are far away could be less detailed. Also, the financial cost is quite high in terms of obtaining technical equipment, such as HTC Vive Pro and PC station, which need to have an exact parameter specification in order to display virtual environment. During this case study, two students were moved from a virtual training group with glasses to another group as they had a problem wearing these glasses. As they were unable to recognize individual parts of an assembly process, it was comfortable enough for them and therefore, we would not have been able to get relevant data from their measurements. Virtual environment tolerance is not equal for all users.

\subsection{What Industrial Sectors Use Virtual Training?}

Technological processes and equipment are closely linked to industrial risks. This is a process of assessing the projected decline to a satisfactory level and continuously monitoring the risks for organizations [27]. It is possible to help manufacturing and non-manufacturing organizations or specialists with the support of virtual and augmented reality applications. It is very important to find solutions using new and effective approaches [28]. Industrial virtual training could be divided into several areas. This could be seen in Figure 13.

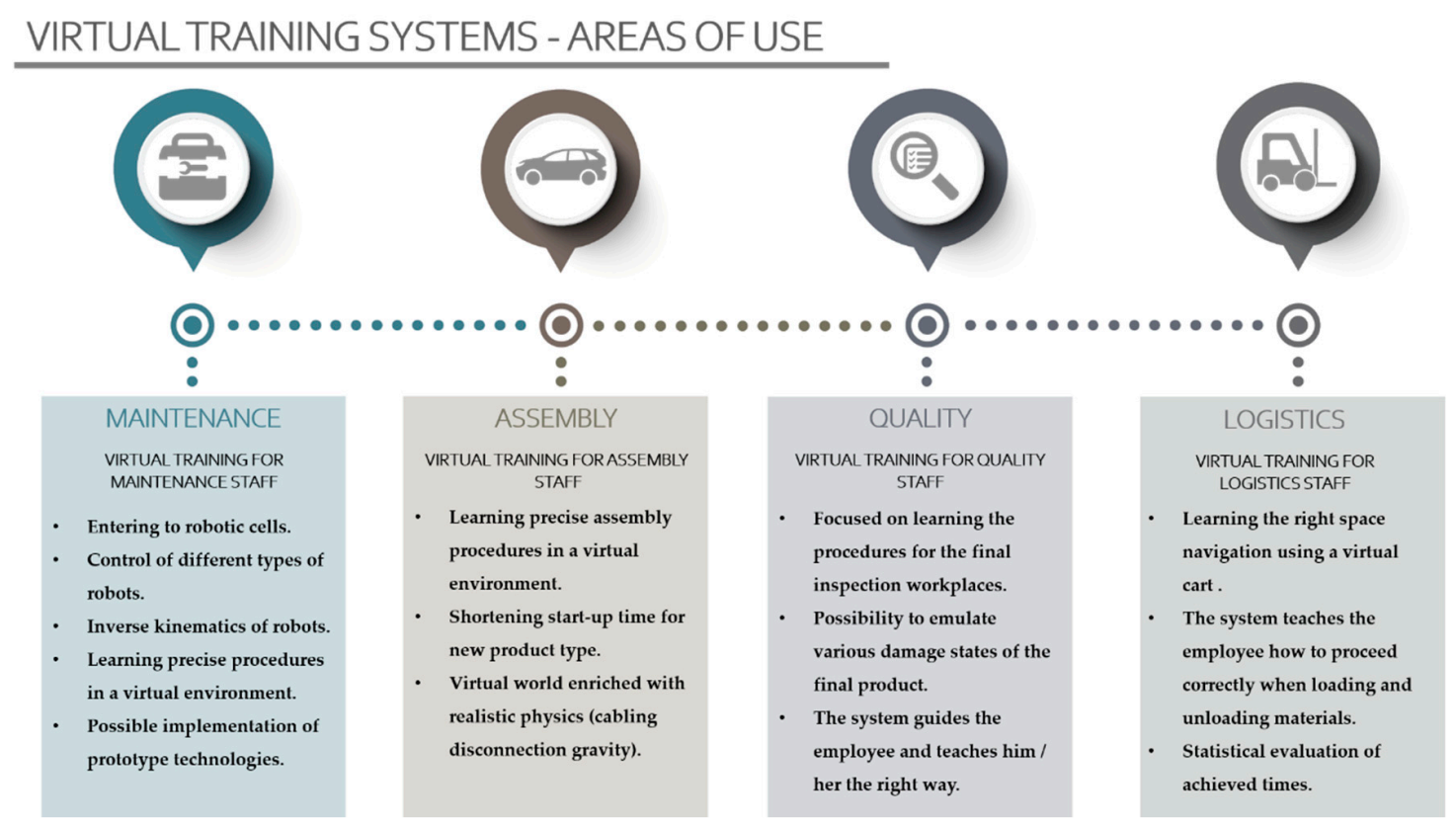

Figure 13. Virtual training types.

These options can be used for a complex assembly and sequence tasks (Figure 14). Thanks to virtual training repetition, an employee's performance quickly improves and potential costly problems, which could have an impact on production, are overcome. These include assembly procedure trainings, virtual reality associated with real objects in production (cables, electric boxes, tools and more), visualization and fault correction in real time, and gear unit interaction. Virtual trainings are also used for very sophisticated products such as industrial robots, CNC, and other machines. This category includes industrial robot management, training for robotic cell units, security rule testing, wrong part exchange, production monitoring in real time, and robot collision investigation. Virtual training focused on field of check-up is used to visualize damages, missing parts, and imperfections. A trainee 
must be able to recognize mistakes of a final product so the training could be finished. This group includes a final product check-up, visualization of various damage types, visualization of missing parts and training models helping employees to learn and practise correct check-up procedures, navigation, monitoring navigation and performance mistakes, visualization of company layouts, material loading, and unloading training. Moreover, logistics use vehicle and hybrid systems for virtual training. These are applied to train operators, and loading and unloading procedures. Also, company navigation training belongs to this category, as well as navigation and performance mistake monitoring, company layout visualization, and material loading and unloading training.

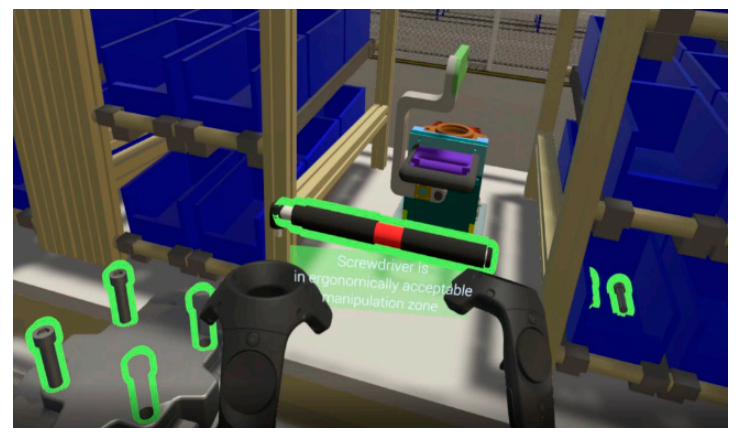

(a)

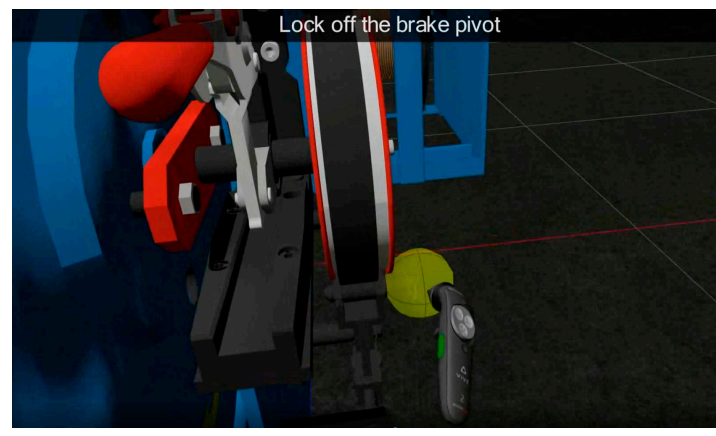

(b)

Figure 14. Demonstration of virtual training in practice. (a) Virtual training for assembly; (b) Virtual training for coil change.

In the case study, students were able to familiarize themselves with the advantages as well as the disadvantages of virtual training. They were allowed to assemble individual components after they improved during assembly training. When interviewed, they were satisfied with this type of training, as they got more proficient and reduced the risk of faults during the assembly process. This virtual training meant there was more acceptable and effective development of their skills and competences. Also, this form of teaching was different and more interesting for them.

\section{Conclusions}

This article describes virtual and augmented reality applications into the technology enhanced learning process at the Department of Industrial Engineering at the University of Žilina (Digital Factory module). The proposed case study points out how helpful immersive technologies could be in a teaching process. This case study was implemented through chronometry and included three groups of students, with each group comprising of 30 students. The main task of these students was to assemble an industrial plug first without any help of virtual technologies, in other words, only with help of the paper form of a user manual. Subsequently, they were asked to assemble the industrial plug with the help of augmented and virtual reality. The results were then written down in a chronometry list, analyzed, and evaluated. This study can conclude that virtual element involvement into a teaching process has a significant benefit in the study of industrial plug assembly, as it reduced the time needed to complete a task by $44.07 \%$. Virtual reality is an interesting element for students in a teaching process. It provides a different view of pedagogical methods, procedures, and elements.

Conducting experiments is a requirement for innovative technology implementation into a teaching process at universities. This was required due to cooperation with Slovak industrial companies. Virtual training could be used in any industrial production area, mainly for a professional employee training. Also, training could be achieved in a small space. There is no need to create a whole production system, as one part is enough. The main benefit for a company is better employee participation in various tasks, cost reduction, as well as the possibility of training in various fields where there is a risk of damaging parts. 
Long sustainability of production companies could be seen via tools, which could be help companies increase the sustainability of their existence and prosperity. Thanks to innovative technologies (such simulation technologies, virtual and augmented reality), companies can easily design and verify the accuracy of new production solutions before the process begins in the space itself $[29,30]$. Each company should put effort into achieving long sustainability and development. Technology enhanced learning and the use of innovative technologies as a virtual and augmented reality serve this purpose.

Author Contributions: Conceptualization, B.F. and P.G.; methodology, G.G. and M.K.; software, G.G.; validation, I.M.; formal analysis, I.M.; resources, G.G., B.F. and R.F.; data curation, R.F.; visualization, P.G.; supervision, M.K.

Funding: This work was supported by the Slovak Research and Development Agency under the Contract no. APVV-18-0522.

Acknowledgments: The authors want to acknowledge the support of CEIT (Central European Institute of Technology) in Žilina.

Conflicts of Interest: The authors declare no conflict of interest.

\section{References}

1. De Pablos, P.O.; Lytras, M.D.; Visvizi, A.; Zhang, X. Opportunities for Information Technologies and Knowledge Management to Answer Emerging Challenges for Manufacturing and Services Industries in the Digital Economy. Hum. Factors Man. 2019, 29, 3-4. [CrossRef]

2. Daniela, L.; Visvizi, A.; Gutiérrez-Braojos, C.; Lytras, M. Sustainable Higher Education and Technology-Enhanced Learning (TEL). Sustainability 2018, 10, 3883. [CrossRef]

3. Brahimi, T.; Sarirete, A. Learning Outside the Classroom through MOOCs. Comput. Hum. Behav. 2015, 51, 604-609. [CrossRef]

4. Visvizi, A.; Lytras, M.; Daniela, L. Education, innovation and the prospect of sustainable growth and development. In The Future of Innovation and Technology in Education: Policies and Practices for Teaching and Learning Excellence, 1st ed.; Visvizi, A., Ed.; Emerald Studies in Higher Education, Innovation and Technology; Emerald Publishing: Bingley, UK, 2019.

5. Saunders, F.C.; Gale, A.W. Digital or Didactic: Using Learning Technology to Confront the Challenge of Large Cohort Teaching: Technology in Large Cohort Teaching. Br. J. Educ. Technol. 2012, 43, 847-858. [CrossRef]

6. Molina-Carmona, R.; Pertegal-Felices, M.L.; Jimeno-Morenilla, A.; Mora-Mora, H. Assessing the impact of Virtual Reality on engineering students' spatial ability. In The Future of Innovation and Technology in Education: Policies and Practices for Teaching and Learning Excellence, 1st ed.; Visvizi, A., Ed.; Emerald Studies in Higher Education, Innovation and Technology; Emerald Publishing: Bingley, UK, 2019.

7. Lytras, M.D.; Aljohani, N.R.; Visvizi, A.; Ordonez De Pablos, P.; Gasevic, D. Advanced Decision-Making in Higher Education: Learning Analytics Research and Key Performance Indicators. Behav. Inf. Technol. 2018, 37, 937-940. [CrossRef]

8. Lytras, M.D.; Damiani, E.; Mathkour, H. Virtual Reality in Learning, Collaboration and Behaviour: Content, Systems, Strategies, Context Designs. Behav. Inf. Technol. 2016, 35, 877-878. [CrossRef]

9. Hays, R.T.; Jacobs, J.W.; Prince, C.; Salas, E. Requirements for Future Research in Flight Simulation Training: Guidance Based on a Meta-Analytic Review. Int. J. Aviat. Psychol. 1992, 2, 143-158. [CrossRef]

10. Zyda, M. Why the VR You See Now Is Not the Real VR. Presence Teleoperators Virtual Environ. 2016, 25, 166-168. [CrossRef]

11. Lele, A. Virtual Reality and Its Military Utility. J. Ambient Intell. Human. Comput. 2013, 4, 17-26. [CrossRef]

12. Bryson, S. Virtual Reality in Scientific Visualization. Comput. Graph. 1993, 17, 679-685. [CrossRef]

13. Omer, M.; Margetts, L.; Hadi Mosleh, M.; Hewitt, S.; Parwaiz, M. Use of Gaming Technology to Bring Bridge Inspection to the Office. Struct. Infrastruct. Eng. 2019, 15, 1292-1307. [CrossRef]

14. Use of Gaming and Affordable VR Technology for the Visualization of Complex Flow Fields. Available online: https://www.researchgate.net/publication/327189667_Use_of_gaming_and_affordable_VR_ technology_for_the_visualization_of_complex_flow_fields (accessed on 16 September 2019).

15. Nonny De La Pena: Pioneering VR and Immersive Journalism. Available online: http://vfxvoice.com/nonnyde-la-pena-pioneering-vr-and-immersive-journalism (accessed on 13 September 2019). 
16. 10 Amazing Uses of Virtual Reality. Available online: http://www.foxnews.com/us/2016/08/22/10-amazinguses-virtual-reality.html (accessed on 12 September 2019).

17. Lytras, M.D.; Mathkour, H.I.; Abdalla, H.; Al-Halabi, W.; Yanez-Marquez, C.; Siqueira, S.W.M. An Emerging-Social and Emerging Computing Enabled Philosophical Paradigm for Collaborative Learning Systems: Toward High Effective next Generation Learning Systems for the Knowledge Society. Comput. Hum. Behav. 2015, 51, 557-561. [CrossRef]

18. Szekely, E.; Mason, M. Complexity Theory, the Capability Approach, and the Sustainability of Development Initiatives in Education. J. Educ. Policy 2019, 34, 669-685. [CrossRef]

19. Hermann, M.; Pentek, T.; Otto, B. Design Principles for Industrie 4.0 Scenarios. In Proceedings of the 2016 49th Hawaii International Conference on System Sciences (HICSS), Koloa, HI, USA, 5-8 January 2016; pp. 3928-3937. [CrossRef]

20. Roldán, J.J.; Crespo, E.; Martín-Barrio, A.; Peña-Tapia, E.; Barrientos, A. A Training System for Industry 4.0 Operators in Complex Assemblies Based on Virtual Reality and Process Mining. Robot. Comput. Integr. Manuf. 2019, 59, 305-316. [CrossRef]

21. Inkinen, H. Review of Empirical Research on Knowledge Management Practices and Firm Performance. J. Knowl. Manag. 2016, 20, 230-257. [CrossRef]

22. Hislop, D. Knowledge Management in Organizations: A Critical Introduction, 3rd ed.; Oxford University Press: Oxford, UK, 2013.

23. Kyza, E.A.; Erduran, S.; Tiberghien, A. Technology-Enhanced Learning in Science. In Technology-Enhanced Learning; Balacheff, N., Ludvigsen, S., de Jong, T., Lazonder, A., Barnes, S., Eds.; Springer: Dordrecht, The Netherlands, 2009. [CrossRef]

24. Mihelj, M.; Novak, D.; Beguš, S. Virtual Reality Technology and Applications; Intelligent Systems, Control and Automation: Science and Engineering; Springer: Dordrecht, The Netherlands, 2014; Volume 68. [CrossRef]

25. Dulina, L.; Bartanusova, M. CAVE Design Using in Digital Factory. Procedia Eng. 2015, 100, $291-298$. [CrossRef]

26. Khan, W.A.; Raouf, A.; Cheng, K. Virtual Manufacturing; Springer Series in Advanced Manufacturing; Springer: London, UK, 2011. [CrossRef]

27. Hollá, K.Z.; Ristvej, J.; Šimák, L. Systematic Method of Risk Assessment in Industrial Processes; WIT Press: Algarve, Portugal, 2010; pp. 115-126. [CrossRef]

28. Gašová, M.; Gašo, M.; Štefánik, A. Advanced Industrial Tools of Ergonomics Based on Industry 4.0 Concept. Procedia Eng. 2017, 192, 219-224. [CrossRef]

29. Trebuňa, P.; Kliment, M.; Edl, M.; Petrik, M. Creation of Simulation Model of Expansion of Production in Manufacturing Companies. Procedia Eng. 2014, 96, 477-482. [CrossRef]

30. Ďurišová, J.; Čambál, M. Impact of Multiculturalism on the Industrial Enterprises Management. Procedia Econ. Financ. 2015, 34, 663-669. [CrossRef]

(C) 2019 by the authors. Licensee MDPI, Basel, Switzerland. This article is an open access article distributed under the terms and conditions of the Creative Commons Attribution (CC BY) license (http://creativecommons.org/licenses/by/4.0/). 